\title{
Structure and Some Physical Properties of Chemically Deposited Nickel Sulfide Thin Films
}

\author{
A.H. HammaD*, Z.S. Elmandouh, H.A. Elmeleegi \\ Electron Microscope and Thin Films Department, Physics Division, National Research Centre, \\ Dokki, 12311, Cairo, Egypt
}

\begin{abstract}
$\mathrm{Ni}_{2} \mathrm{~S}_{2-x}$ thin films with $x=0,0.5$, and 1 were prepared by chemical bath deposition technique. Amorphous structure was discovered by XRD for $x=1$, while $\alpha-\mathrm{Ni}_{7} \mathrm{~S}_{6}$ and $\mathrm{NiS}$ phases were discovered for $x=0$, and $x=0.5$ respectively. SEM graphs of the studied films have confirmed the XRD results. Optical band gap values increase from 0.845 to $0.912 \mathrm{eV}$, with increase of the composition $x$ from 0 to 1 . Activation energy values increase in the range from $x=0$ to $x=0.5$ and does not change for $x=1$.
\end{abstract}

DOI: $10.12693 /$ APhysPolA.127.901

PACS: 61.05.cp, 68.37.Hk, 68.55.jd, 68.55.J-, 78.20.Ci, 78.68. $+\mathrm{m}, 73.50 . \mathrm{Lw}, 73.90 .+\mathrm{f}$

\section{Introduction}

Metal chalcogenides (sulfides, selenides, and tellurides) have interesting technological applications in various devices such as solar selective coatings, IR detectors, photoconductors, sensors, etc. [1, 2].

Nickel sulfide compounds have different phases such as $\mathrm{Ni}_{3+x} \mathrm{~S}_{2}, \mathrm{Ni}_{3} \mathrm{~S}_{2}, \mathrm{Ni}_{4} \mathrm{~S}_{3+x}, \mathrm{Ni}_{6} \mathrm{~S}_{5}, \mathrm{Ni}_{7} \mathrm{~S}_{6}, \mathrm{Ni}_{9} \mathrm{~S}_{8}, \mathrm{NiS}$, $\mathrm{Ni}_{3} \mathrm{~S}_{4}$, and $\mathrm{NiS}_{2}[3,4]$. NiS phase has high temperature hexagonal $(\alpha-\mathrm{NiS})$ and low temperature rhombohedral $(\beta-\mathrm{NiS})$ phases [3]. $\quad \mathrm{NiS}_{2}$ has pyrite structure with $\mathrm{Ni}$ atoms arranged in fcc lattice which imparts a magnetic frustration in the system [4]. On the other hand, S-atom is located in body centered cubic structure of $\mathrm{Ni}_{3} \mathrm{~S}_{2}$ phase with $\mathrm{Ni}$ atoms in some of the pseudo-tetrahedral holes $[4,5] . \mathrm{Ni}_{7} \mathrm{~S}_{6}$ can be formed from $\mathrm{Ni}_{9} \mathrm{~S}_{8}$ and $\mathrm{Ni}_{3} \mathrm{~S}_{2}$ eutectoidally and is structurally related to the high temperature $\mathrm{Ni}_{7 \pm x} \mathrm{~S}_{6}$ phase $[4,6]$.

Chemical bath deposition technique is an important method for depositing of metal chalcogenide thin films due to its simplicity, and it doesn't require special equipment or expensive devices. Few reports were dealt on nickel sulfide thin films prepared by chemical routes [7-10].

In the present study, $\mathrm{Ni}_{2} \mathrm{~S}_{2-x}$ thin films with different content of sulfur were chemically deposited onto commercial glass substrate at room temperature. The structure, morphology, optical, electrical, and transport properties were investigated in order to characterize the physical properties of NiS thin films.

\section{Experimental details}

\subsection{Preparation of $\mathrm{Ni}_{2} S_{2-x}$ thin films by $\mathrm{CBD}$}

Before making chemical deposition onto glass substrates, the substrates were immersed in $150 \mathrm{ml}$ beaker containing a solution of diluted $10 \% \mathrm{HCl}$ for 15 minutes.

\footnotetext{
*corresponding author; e-mail: ahosny2005@gmail.com
}

Then the slides are ultrasonically cleaned for $15 \mathrm{~min}$ in ethyl alcohol, acetone and distilled water and finally the substrates were dried in air.

The following procedure, which is a modified version of the procedure from [7], was used to deposit the $\mathrm{Ni}_{2} \mathrm{~S}_{2-x}$ films for $x=0,0.5$, and 1 respectively. $10 \mathrm{ml}$ of $0.8 \mathrm{M}$ of $\mathrm{NiSO}_{4} \cdot 6 \mathrm{H}_{2} \mathrm{O}$ solution was added to $7.4 \mathrm{M}$ of triethanolamine (TEA) under continuous stirring for 2 minutes. Ammonia solution (25\%) is used to adjust the $\mathrm{pH}$ value to 11 with continuous stirring for $5 \mathrm{~min} .10 \mathrm{ml}$ of thioacetamide was slowly added to the bath and the glass substrates were vertically immersed into the solution. Finally, double distilled water was added to increase the total volume of the bath up to $100 \mathrm{ml}$. The substrates were removed from the bath after $4 \mathrm{~h}$, washed several times with double distilled water and finally dried. The observed films have a good adhesion to glass substrates.

\subsection{Characterization}

An X-ray diffraction (type Panalytical X'Pert PRO) secondary monochromator, with $\mathrm{Cu} \mathrm{K}_{\alpha}$ radiation $(\lambda=$ $0.154059 \mathrm{~nm}$ ), operating at $45 \mathrm{kV}$ and $40 \mathrm{~mA}$ was used in the present work in the $2 \theta$ range of $25-70^{\circ}$. All of the investigated thin films were studied by SEM (type JXA-840A Electron Probe Microanalyzer operated at $30 \mathrm{kV}$ ). Energy dispersive X-ray (EDAX) analyser (LEICA.S44Oi) was used to confirm the presence of the constituents of the films. UV-vis-NIR spectrophotometer type JASCO 570 REV 1.00 was used for optical studies in the range of 30-2500 $\mathrm{nm}$. Electrical conductivity measurements were carried out in the temperature range 298-493 K. The electrical resistance, $R$, was measured by means of a high impedance electrometer $\left(10^{19} \Omega\right)$ type, Keithely 6517 B.

\section{Results and discussion}

\subsection{XRD investigation}

Figure 1, shows the XRD spectra for $\mathrm{Ni}_{2} \mathrm{~S}_{2-x}$ thin films. It is clearly seen that the structure of the films is strongly dependent on the $x(\mathrm{Ni} / \mathrm{S}$ ratio). As seen in 


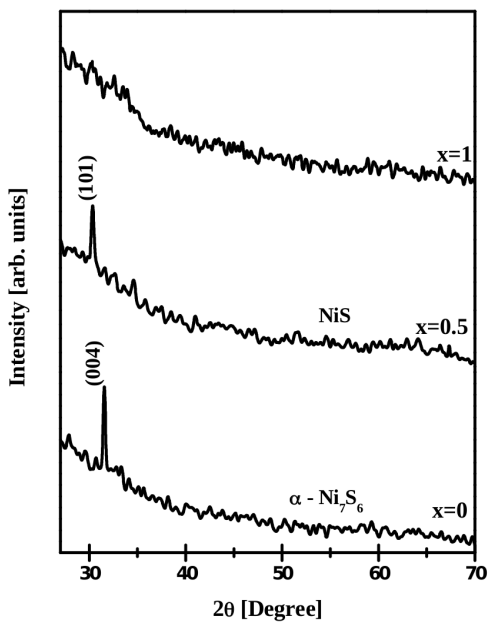

Fig. 1. XRD patterns for the $\mathrm{Ni}_{2} \mathrm{~S}_{2-x}$ thin films.

Fig. 1, sharp peak of crystalline phase $\alpha-\mathrm{Ni}_{7} \mathrm{~S}_{6}$ (JCPDS 25-0583) and NiS (JCPDS 12-0041) is detected for $x=0$ $(\mathrm{Ni} / \mathrm{S}=1)$ and $0.5(\mathrm{Ni} / \mathrm{S}=4 / 3)$ respectively, while amorphous nature is observed for films having $x=1(\mathrm{Ni} / \mathrm{S}=2)$, so the EDAX analysis was carried out to obtain the composition of this film. The present result for sample containing $\mathrm{Ni} / \mathrm{S}=1$ or $x=0$ is quite different from those obtained previously (NiS phase) by Pramanik and Biswas [7]. It may be due to the different method of preparation. The crystallite size in the deposited films $(x=0$ and 0.5$)$ was calculated to be $9.9 \mathrm{~nm}$ and $12.5 \mathrm{~nm}$, respectively using Scherrer's equation as follows:

$$
D=\frac{0.9 \lambda}{\beta \cos \theta},
$$

where $\lambda=0.154056 \mathrm{~nm}\left(\mathrm{Cu}-\mathrm{K}_{\alpha}\right.$ radiation $), \beta$ is the full width at half maximum and $\theta$ is the angle in radians.

\subsection{Compositional and morphological analysis}

It is clearly seen that smooth and continuous film with amorphous nature is observed for $x=1$ as shown in Fig. 2c. On the other hand, condensed spherical particles are observed in the films of composition $x=0$ (Fig. 2a) Films of composition $x=0.5$ have a smooth surface with some aggregated particles, as it is clearly seen in Fig. 2 b.
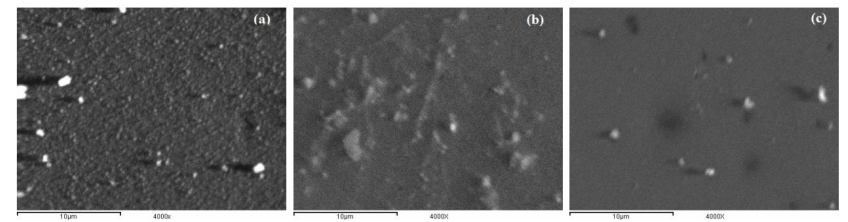

Fig. 2. SEM micrographs for $\mathrm{Ni}_{2} \mathrm{~S}_{2-x}$ thin films, (a) $x=0$, (b) $x=0.5$, (c) $x=1$.

The film thicknesses measured by SEM are 285, 230, and $100 \mathrm{~nm}$ for $x=0,0.5$, and 1 , respectively. The smallest film thickness $(100 \mathrm{~nm})$ for $x=1$ explains the amorphous structure obtained from XRD analysis, which reflects the structure of ordinary glass substrate.

\subsection{Optical properties of $\mathrm{Ni}_{2} \mathrm{~S}_{2-x}$ thin films}

The transmittance spectra of CBD nickel sulfide thin films are presented in Fig. 3a. In order to determine the optical band gap $\left(E_{g}\right)$ and the other optical constants [11] for all films the absorption coefficient $(\alpha)$ should be calculated from the expression:

$$
\alpha=(1 / d) \ln (1 / T),
$$

where $d$ is the film thickness in units of $\mathrm{cm}$, and $T$ is the transmittance. The extinction coefficient $(k)$ is correlated with the absorption coefficient $(\alpha)$ by the relation $k=\alpha \lambda / 4 \pi$. The optical band gap for the studied films can be determined as described elsewhere [11]. The values of $E_{g}$ for the studied films are higher than ones reported in the literature [7] $(0.35 \mathrm{eV})$ and are lower than ones obtained by Ubale and Bargal [10] $(0.92 \mathrm{eV})$. On the other hand, the energy gap of the studied films is related to the linear refractive index $\left(\mathrm{n}_{0}\right)$ by the expression [12]

$$
\sqrt{\frac{5}{E_{g}}}=\frac{n_{0}^{2}+2}{6} .
$$

The values of optical band gap, refractive index, absorption coefficient, and extinction coefficient are shown in Table. The optical band gap values are observed to increase as the film composition parameter $(x)$ increases. This behavior may be attributed to the quantum size effect of the studied films.
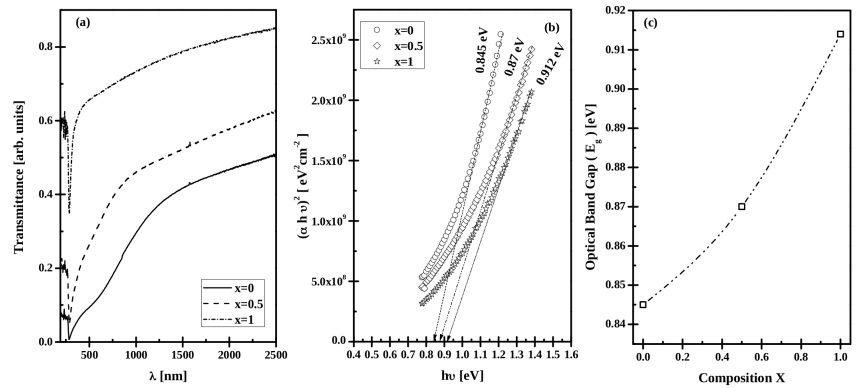

Fig. 3. (a) Transmittance spectra of $\mathrm{Ni}_{2} \mathrm{~S}_{2-x}$ thin films, (b) Plot of $(\alpha h v)^{1 / 2}$ vs. photon energy for $\mathrm{Ni}_{2} \mathrm{~S}_{2-x}$ thin films, and (c) dependence of optical band gap on the film composition.

Optical band gap, $E_{g}$, linear refractive index, $n_{0}$, absorption coefficient, $\alpha$, and extinction TABLE coefficient, $k$ for $\mathrm{Ni}_{2} \mathrm{~S}_{2-x}$ thin films.

\begin{tabular}{c|c|c|c|c}
\hline \hline$x$ & $E_{g}[\mathrm{eV}]$ & $n_{0}$ & $\alpha\left[\mathrm{cm}^{-1}\right]$ at $1000 \mathrm{~nm}$ & $k$ at $1000 \mathrm{~nm}$ \\
\hline 0 & 0.845 & 3.548 & $42.778 \times 10^{3}$ & 0.340 \\
\hline 0.5 & 0.870 & 3.520 & $33.767 \times 10^{3}$ & 0.268 \\
\hline 1 & 0.912 & 3.471 & $31.065 \times 10^{3}$ & 0.247
\end{tabular}

\subsection{Electrical properties of $\mathrm{Ni}_{2} \mathrm{~S}_{2-x}$ thin films}

The variation of dc conductivity of the samples over the temperature range $303-493 \mathrm{~K}$ is shown in Fig. 4, for different composition parameters $x$. It is observed that all films show Arrhenius-type behavior. The activation 
energy $\left(\mathrm{E}_{a}\right)$ was calculated using Arrhenius relation, as stated in the following expression [13]:

$$
\sigma=\sigma_{0} \exp \left(-E_{a} / k_{\mathrm{B}} T\right),
$$

where $\sigma$ is the conductivity at temperature $T, \sigma_{0}$ is a constant, $k_{\mathrm{B}}$ is the Boltzmann constant, $T$ is the absolute temperature. The activation energies were determined from the slope of the plotted curves $[\ln (\sigma)$ vs. $1 / T]$ at higher temperatures. The activation energy is observed to increase as the $x$ parameter increases from $x=0$ to $x=0.5$ and is approximately constant at $x=1$.
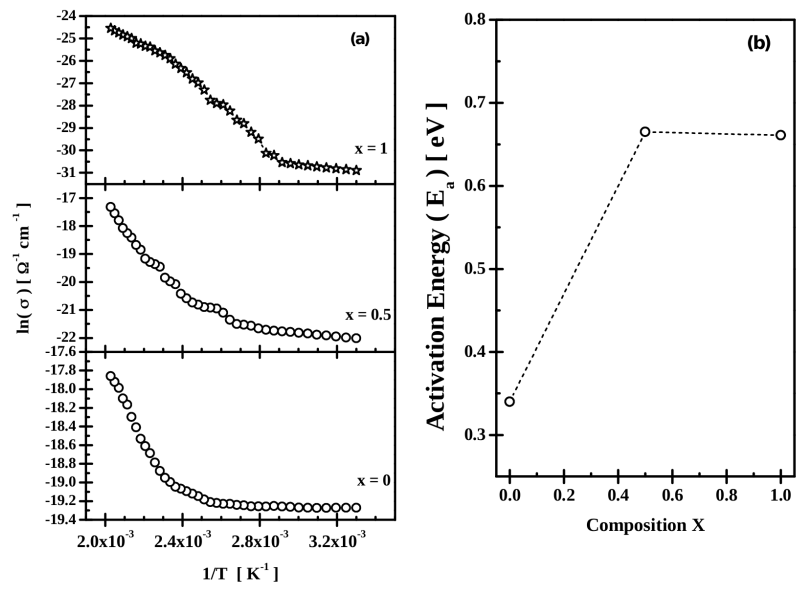

Fig. 4. (a) Plots of $\ln (\sigma)$ vs. $1 / T$, (b) Plot of $E_{a}$ vs. composition $x$.

\section{Conclusions}

Nickel sulfide thin films have been prepared via chemical bath deposition route. Films of thickness greater than $230 \mathrm{~nm}$ show a polycrystalline phase, while films of lower thickness of about $100 \mathrm{~nm}$ have amorphous nature. The slight increase of nickel content is favorable to form NiS phase with homogeneous film surface. Optical and electrical properties of the studied films show that optical band gap and activation energy are strongly affected by the $\mathrm{Ni} / \mathrm{S}$ ratio or the composition $x$.

\section{References}

[1] R.S. Mane, C.D. Lokhande, Mater. Chem. Phys. 65, 1 (2000).

[2] A.M. Salem, M.S. Selim, J. Phys. D. Appl. Phys. 34, 12 (2001).

[3] G. Kullerud, R.A. Yund, J. Petrol. 3, 126 (1962).

[4] N. Kumar, N. Raman, A. Sundaresan, J. Solid State Chem. 208, 103 (2013).

[5] K. Ramasamy, M.A. Malik, P. O'Brien, J. Raftery, M. Helliwell, Chem. Mater. 22, 6328 (2010).

[6] H.Seim, H. Fjellvâg, F. Grønvold, S.Stølen, J. Solid State Chem. 121, 400 (1996).

[7] P. Pramanik, S. Biswas, J. Solid State Chem. 65, 145 (1986).

[8] S.D. Sartale, C.D. Lokhande, Mater. Chem. Phys. 72, 101 (2001).
[9] F. Atay, S.Köse, V.Bilgin, İ. Akyüz, Turk. J. Phys. 27, 285 (2003).

[10] A.U. Ubale, A.N. Bargal, Mater. Res. Bull. 46 , 1000 (2011).

[11] A. Sawaby, M.S. Selim, S.Y. Marzouk, M.A. Mostafa, A. Hosny, Physica B 405, 3412 (2010).

[12] R.N. Chauhan, R.S. Anand, J. Kumar, Thin Solid Films 556, 253 (2014).

[13] A. Hakim, J. Hossain, K.A. Khan, Renewable Energy 34, 2625 (2009). 